\title{
ANALISIS PENGUNGKAPAN EMISI GAS RUMAH KACA
}

\author{
Anistia Prafitri \\ Zulaikha
}

Departemen Akuntansi Fakultas Ekonomika dan Bisnis Universitas Diponegoro

\begin{abstract}
This study aimes to examine the effect of environmental management system, company's environmental performance, company size, industry type, return on asset and leverage on the greenhouse gas emissions disclosures. The population are the agriculture, energy, transportation, base and chemical companies listed on the Stock Exchange in the year 20142015. Total samples used are 298 companies. Logistic regression is used to test the hypothesis. The results indicate that there is a positive and significant effect of the environmental management system, the company's environmental performance, company size, industry type, and leverage on the disclosures of greenhouse gas emissions, but return on asset don't have effect on them.
\end{abstract}

Keywords: disclosure of greenhouse gas emissions, environmental management systems, company size, return on asset.

\section{PENDAHULUAN}

Berubahnya iklim secara global yang tidak terkendali menyebabkan munculnya berbagai permasalahan. Menurut Griffith et al, 2007 pemanasan global dan risiko perubahan iklim diakui secara internasional sebagai masalah yang signifikan bagi perusahaan. Bukti ilmiah menunjukan bahwa gas rumah kaca dari aktivitas manusia memperburuk pemanasan global dan perubahan iklam (IPCC, 2007). Aktivitas manusia yang paling besar menyumbang emisi gas rumah kaca adalah aktivitas industri. Perusahaan sebagai pelaku ekonomi yang menjalankan aktivitas industri memiliki peluang besar menghasilkan emisi gas rumah kaca.

Terdapat regulasi global yang menjawab permasalahan mengenai pemanasan global dan perubahan iklim ini, dengan memberikan mandat untuk mengungkapan emisi gas rumah kaca pada setiap entitas perusahaan. The United Nation (PBB) mengembangkan Kyoto Protocol sebagai upaya untuk penurunan emisi gas rumah kaca. Pemerintah Indonesia juga merespon upaya penurunan emisi gas rumah kaca dengan mengeluarkan Undang-Undang Nomor 17 tahun 2004 tentang Pengesahan Kyoto 
Protocol to The United Nations Framework Convention on Climate Change. Komitmen Indonesia untuk mengurangi emisi gas rumah kaca juga dapat dilihat dari dikeluarkannya Perpres No. 61 Tahun 2011 mengenai Rencana Aksi Nasional Penurunan Emisi Gas Rumah Kaca dan Perpres No. 71 Tahun 2011 mengenai penyelenggaraan inventarisasi gas rumah kaca nasional. Pada pasal 4 Perpres No. 61 Tahun 2011, disebutkan bahwa pelaku usaha juga ikut andil dalam upaya penurunan emisi gas rumah kaca. Upaya pengurangan emisi gas rumah kaca yang dilakukan oleh perusahaan sebagai pelaku usaha dapat diketahui dari pengungkapan emisi karbon.

Perusahaan memiliki tanggung jawab untuk berperan aktif dalam melaporkan informasi terkait kinerja perusahaan termasuk kinerja lingkungannya. Masyarakat dan stakeholders memiliki hak untuk mendapatkan informasi yang memadai mengenai kinerja perusahaan termasuk kinerja lingkungan. Bentuk komunikasi dan tanggung jawab perusahaan terkait kinerja lingkungan salah satunya adalah dengan pengungkapan emisi gas rumah kaca di dalam laporan perusahaan. Laporan ini nantinya dapat digunakan oleh pihak yang berkepentingan untuk mengevaluasi perusahaan dan digunakan dalam pengambilan keputusan. Oleh karena itu pengungkapan ini merupakan dasar bagi transparasi perusahaan untuk menginformasikan kepada masyarakat dan stakeholders tentang bagaimana perusahaan mengatasi resiko yang terjadi dari adanya perubahan iklim dan pemanasan global (CDP, 2009).

Beberapa penelitian terkait pengungkapan emisi gas rumah kaca di negara maju telah banyak dilakukan. Penelitian Rankin et al (2011) mengungkapkan bahwa faktor yang berpengaruh positif terhadap pengungkapan emisi gas rumah kac adalah sistem manajemen lingkungan, tata kelola perusahaan, corporate disclosure project (CDP), ukuran perusahaaan dan tipe industri. Penelitian oleh Gonzales (2016) menyebutkan dalam kasus Spanyol, faktorfaktor yang menunjukkan pengaruh yang kuat dalam mempengaruhi pengungkapan emisi gas rumah kaca adalah ukuran perusahaan, risiko keuangan, perusahaan yang masuk dalam indeks IBEX35 dan FT500 dan konsentrasi kepemilikan perusahaan.

Penelitian mengenai emisi gas rumah kaca pada perusahaan di Indonesia 
sendiri masih terbatas. Pengungkapan emisi gas rumah kaca di Indonesia masih merupakan pengungkapan sukarela dan praktiknya masih jarang dilakukan oleh entitas bisnis. Perusahaan yang melakukan pengungkapan emisi karbon memiliki beberapa pertimbangan diantaranya untuk mendapatkan legitimasi dari para stakeholder, menghindari ancamanancaman terutama bagi perusahaanperusahaan yang menghasilkan gas rumah kaca seperti peningkatan biaya operasi, pengurangan permintaan, risiko reputasi, proses hukum, serta denda dan pinalti (Berthelot dan Robert, 2011).

Penelitian terdahulu didominasi pada faktor yang mempengaruhi pengungkapan sosial lingkungan, tidak spesifik terhadap pengungkapan emisi gas rumah kaca. Penelitian yang spesifik meneliti pengungkapan emisi gas rumah kaca pun menemukan hasil yang beragam. Penelitian ini berfokus pada faktor apa saja yang mempengaruhi pengungkapan emisi gas rumah kaca perusahaan di Indonesia.

KERANGKA PEMIKIRAN TEORITIS DAN PERUMUSAN HIPOTESIS

Perusahaan menjalankan usaha dan bisnisnya di tengah-tengah kehidupan masyarakat dengan berbagai kebutuhan dan tujuan yang berusaha untuk dipenuhinya. Dalam pelaksanaan dan pencapaiannya tidak hanya untuk kepentingan perusahaan sendiri yang diperhatikan namun juga memperhatikan kepentingan masyarakat. Masyarakat memiliki pengaruh yang besar terhadap aktivitas perusahaan. Salah satunya adalah permintaan masyarakat serta stakeholders yang lainnya agar perusahaan memperhatikan masalah lingkungan. Perusahaan merespon permintaan tersebut dengan memberikan informasi yang kredibel atas kinerja lingkungan. Teori legitimasi membantu perusahaan untuk menyesuaikan diri dengan harapan masyarakat atau sebagai cara untuk mempertahankan atau mendapatkan kembali legitimasi ( Owen, 2008)

Purnomosidhi (2006) menyatakan bahwa stakeholder memiliki hak untuk diberikan informasi tentang bagaimana aktivitas perusahaan mempengaruhi mereka meskipun informasi tersebut tidak mereka gunakan, atau tidak memainkan peranan signifikan dalam perusahaan. Informasi tersebut tidak hanya terkait kinerja keuangan saja namun informasi terkait kinerja lainnya yang akan mempengaruhi kinerja keuangan perusahaan. Kinerja lainnya yang dimaksud seperti kebijakan yang digunakan, keputusan yang akan 
diambil, dan kinerja terkait sosial lingkungan, termasuk pengungkapan emisi gas rumah kaca. Stakeholder memilki kemampuan untuk mengendalikan perusahaan dalam menjalankan aktivitasnya termasuk dalam melakukan pengungkapan Pengungkapan emisi gas rumah kaca masih bersifat sukarela, yang berarti bahwa perusahaan tidak wajib untuk melaporkannya di dalam laporan mereka. Namun beberapa hal yang perlu dipertimbangkan perusahaan dalam penilaian kinerja perusahaan dan upaya keberlanjutan perusahaan mendorong para manajer perusahaan untuk lebih lengkap dan komprehensif dalam mengungkapkan segala informasi tentang perusahaan. Dampak dari emisi gas rumah kaca menjadi masalah yang signifikan bagi perusahaan serta adanya dorongan dari stakeholders adalah beberapa hal yang perlu dipertimbangkan perusahaan dalam penilaian kinerja perusahaan.

Kondisi ini dapat diperbaiki dengan adanya sistem manajemen lingkungan dalam perusahaan, sistem manajemen lingkungan akan mendorong perusahaan untuk lebih banyak mengungkapkan emisi gas rumah kaca nya (Rankin et al, 2011). Sistem manajemen lingkungan akan membantu perusahaan untuk menciptakan kinerja lingkungan yang bagus. Perusahaan dengan kinerja lingkungan yang bagus akan mencoba untuk membedakan diri dengan sukarela mengungkapkan informasi tentang kinerja mereka (Dawkins et al, 2011). Ukuran perusahaan dan tipe industri juga menjadi dorongan bagi perusahaan untuk mengungkapkan informasi mengenai emisi gas rumah kaca. Perusahaan besar akan mendapatkan tekanan yang lebih besar dan memiliki lebih pemegang saham yang mungkin tertarik pada perubahan sosial dan kegiatan lingkungan (Cowen et al, 1987). Perusahaan yang masuk dalam industri yang intensif menghasilkan karbon akan lebih mengungkapkan informasi karbon untuk menunjukkan bahwa mereka bertanggung jawab dan untuk mengurangi ancaman pada legitimasi mereka (Borghei et al, 2016). Besarnya return on asset dan leverage suatu perusahaan juga bisa mendorong perusahaan untuk melakukan pengungkapan terkait lingkungan, salah satunya pengungkapan emisi gas rumah kaca. Clarkson et al (2008), perusahaan yang memiliki keuntungan finansial akan lebih mungkin utuk memberikan pengungkapan lingkungan. Sedangkann perusahaan dengan leverage yang tinggi cenderung lebih berkonsentrasi dalam 
melunasi kewajiban dibandingkan dengan melakukan pengungkapan sukarela.

\section{Pengaruh Sistem Manajemen}

\section{Lingkungan terhadap Pengungkapan}

Emisi Gas Rumah Kaca

Pelaksanaan sistem manajemen lingkungan bagi perusahaan menunjukkan bahwa komitmen perusahaan untuk memantau, mengelola, mengontrol, mengukur dan melaporkan kinerja lingkungannya, termasuk pula pada emisi gas rumah kaca perusahaan (Rankin et al, 2011). Sistem manajemen lingkungan menganut pada Standar Sistem Manajemen ISO 14001 tentang lingkungan. Kebijakan ramah lingkungan merupakan kebijakan yang paling kuat bagi perusahaan untuk menerapkan sistem manajemen lingkungan bersertifikat ISO 14001, sedangkan motif menengah adalah mendapatkan competitive advantage dan motif terendah adalah kebutuhan sosial (Psomas, 2011). Berdasarkan uraian diatas, dapat dirumuskan hipotesis pertama yaitu:

\section{$H_{1}:$ sistem manajemen lingkungan} berpengaruh positif terhadap pengungkapan emisi gas rumah kaca

\section{Pengaruh Kinerja Lingkungan terhadap Pengungkapan Emisi Gas Rumah Kaca}

Kinerja lingkungan dapat dijadikan sebagai salah satu ukuran bagaimana tanggung jawab perusahaan terhadap lingkungannya. Tanggung jawab lingkungan perusahaan mencakup area yang cukup luas, bahkan diluar wilayah perusahaan itu sendiri. Menurut penelitian Dawkins et al (2011), kinerja lingkungan mempunyai hubungan positif dengan pengungkapan lingkungan yaitu terkait emisi gas rumah kaca. Dimana perusahaan dengan catatan kinerja lingkungan yang buruk akan menahan pengungkapan dalam upaya untuk menghindari paparan negatif, sementara perusahaan dengan kinerja lingkungan yang bagus akan mencoba untuk membedakan diri dengan sukarela mengungkapkan informasi tentang kinerja mereka (Dawkins et al, 2011). Hal ini sejalan dengan penelitian Luo et al (2013) yang mengatakan bahwa perusahaan dengan kinerja karbon yang baik akan cenderung untuk memberikan laporan terkait pengungkapan karbon. Menurut Clarkson et al (2008), perusahaan dengan kinerja lingkungan yang unggul memiliki strategi lingkungan yang proaktif. Hal tersebut mendorong perusahaan untuk menginformasikan kepada investor dan 
stakeholder lain melalui pengungkapan sukarela mengenai lingkungan. Berdasarkan uraian diatas, dapat dirumuskan hipotesis kedua yaitu:

\section{$\mathrm{H}_{2}:$ kinerja lingkungan berpengaruh} positif terhadap pengungkapan emisi gas rumah kaca

\section{Pengaruh Ukuran Perusahaan terhadap}

Pengungkapan Emisi Gas Rumah Kaca

Penelitian menunjukkan bahwa ukuran perusahaan mempunyai hubungan yang positif dengan pengungkapan emisi gas rumah kaca (Choi et al, 2013; Lorenzo et al, 2009; Ghomi dan Leung, 2013). Perusahaan yang lebih besar lebih mungkin untuk memberikan pengungkapan secara sukarela karena mereka melakukan kegiatan yang mempengaruhi lingkungan, sehingga menimbulkan pengawasan yang lebih besar dari publik dan pemerintah (Stanny dan Ely, 2008; Prado-Lorenzo et al, 2009). Perusahaan besar berada di bawah tekanan yang lebih tinggi dari masyarakat dan stakeholders, mereka memiliki harapan tinggi tentang praktik manajemen karbon perusahaan. Oleh karena itu, perusahaan besar lebih responsif terhadap tuntutan pengungkapan; adanya hubungan positif antara ukuran perusahaan dan pengungkapan dilaporkan dalam penelitian sebelumnya (Freedman dan Jaggi, 2005). Berdasarkan uraian diatas, dapat dirumuskan hipotesis ketiga yaitu:

\section{$\mathrm{H}_{3}:$ ukuran perusahaan berpengaruh} positif terhadap pengungkapan emisi gas rumah kaca

\section{Pengaruh Tipe Industri terhadap}

Pengungkapan Emisi Gas Rumah Kaca

Beberapa industri mungkin akan menjadi perhatian publik terutama industriindustri dimana operasi bisnisnya akan menghasilkan tingkat gas rumah kaca yang besar dan berbahaya (PWC, 2008). Tidak semua perusahaan yang bergerak di berbagai bidang mengungkapkan aktivitasnya apabila tidak mempunyai nilai yang positif bagi perusahaan tersebut. Untuk jenis perusahaan yang intensif karbon seperti pertanian, energi dan transportasi, serta industri dasar dan kimia yang menghasilkan kerusakan lingkungan dan emisi karbon yang tinggi dibandingkan dengan jenis perusahaan yang non intensif seperti yang bergerak di bidang jasa, perdagangan, dan lain sebagainya. Menurut Wang et al (2013) perusahaan intensif karbon yang aktivitas operasionalnya berdampak negatif terhadap lingkungan cenderung untuk mengungkapkan lebih 
banyak informasi mengenai tanggung jawab sosial perusahaan (CSR) dibandingkan yang non intensif karbon. Hasil penelitian Choi et al (2013) menunjukkan bahwa tingkat pengungkapan emisi karbon secara sukarela akan lebih besar di perusahaan pada industri yang intensif dalam menghasilkan emisi. Berdasarkan uraian diatas, dapat dirumuskan hipotesis keempat yaitu:

H4: tipe industri berpengaruh positif terhadap pengungkapan emisi gas rumah kaca

\section{Pengaruh Return on Asset terhadap}

\section{Pengungkapan Emisi Gas Rumah Kaca}

Perusahaan dengan kondisi keuangan yang baik lebih mungkin mengungkapkan informasi lingkungan. Hal tersebut sejalan dengan penelitian Lang dan Lundholm (1993) yang menyatakan bahwa perusahaan dengan catatan kinerja yang lebih baik lebih memungkinkan untuk mengumumkan kinerjanya. Akibatnya Clarkson et al, 2008 menyimpulkan bahwa perusahaan yang memiliki keuntungan lebih mungkin untuk memberikan pengungkapan lingkungannya. Menurut Choi et al (2013), perusahaan dengan kondisi keuangan yang baik mampu membayar sumber daya tambahan manusia atau keuangan yang dibutuhkan untuk pelaporan sukarela dan pengungkapan emisi karbon yang lebih baik untuk menahan tekanan eksternal. Dan menurut Luo et al (2013) bahwa perusahaan dengan kinerja keuangan baik mempunyai kemampuan secara finansial dalam membuat keputusan terkait lingkungan. Sebaliknya, perusahaan dengan kinerja keuangan kurang baik lebih fokus pada pencapaian tujuan keuangan dan peningkatan kinerja mereka sehingga membatasi kemampuannya dalam upaya pencegahan dan pelaporan emisi karbon. Berdasarkan uraian diatas, dapat dirumuskan hipotesis kelima yaitu:

$\mathrm{H}_{5}:$ return on asset berpengaruh positif terhadap pengungkapan emisi gas rumah kaca

\section{Pengaruh Leverage terhadap}

\section{Pengungkapan Emisi Gas Rumah Kaca \\ Leverage berpengaruh negatif} terhadap pengungkapan karena kewajiban yang lebih besar dari utang dan pembayaran kembali bunga akan membatasi kemampuan perusahaan untuk melakukan strategi pengurangan dan pengungkapan karbon. Perusahaan dengan leverage yang tinggi akan lebih berhati-hati dalam 
mengurangi dan mengungkapkannya terutama menyangkut mengenai pengeluaran-pengeluaran yang berkaitan dengan tindakan pencegahan karbon (Luo et $a l, 2013)$. Perusahaan dengan leverage yang tinggi cenderung lebih berkonsentrasi dalam melunasi kewajiban dibandingkan dengan melakukan pengungkapan sukarela. Hal ini disebabkan karena ketebatasan alokasi dana yang dimiliki, perusahaan harus memilih apakah menggunakan dana tersebut untuk melunasi segala kewajiban mereka ataukah untuk melakukan pengungkapan sukarela. Jadi semakin tinggi leverage perusahaan maka semakin kecil pengungkapan sukarela yang dilakukan dan jika leverage perusahaan kecil makan akan semakin besar pengungkapan sukarela yang dilakukan. Berdasarkan uraian diatas, dapat dirumuskan hipotesis keenam yaitu:

\section{$H_{6}:$ leverage berpengaruh negatif} terhadap pengungkapan emisi gas rumah kaca

\section{METODE PENELITIAN}

Variabel Penelitian

Variabel Dependen

Dalam penelitian ini yang menjadi variabel dependennya adalah pengungkapan emisi gas rumah kaca yang diukur dengan angka dummy. Kode 1 untuk perusahaan yang mengungkapkan informasi mengenai emisi gas rumah kaca dalam laporan mereka dan nilai 0 untuk perusahaan yang tidak mengungkapkan informasi mengenai emisi gas rumah kaca dalam laporan mereka.

\section{Variabel Independen}

Dalam penelitian ini variabel independen yang digunakan adalah sistem manajemen lingkungan, kinerja lingkungan, ukuran perusahaan, tipe industri, return on asset, dan leverage. Pengukuran sistem manajemen lingkungan menggunakan variabel dummy yaitu 1 untuk perusahaan yang memiliki sistem manajemen lingkungan bersertifikat ISO 14001 atau memiliki sistem manajemen lingkungan tanpa sertifikat, dan 0 untuk perusahaan yang tidak memiliki sistem manajemen lingkungan. Kinerja lingkungan diukur dengan menggunakan PROPER. PROPER ini mencakup pemeringkatan perusahaan dalam 5 warna yaitu: Emas (sangat sangat baik, skor 5), Hijau (sangat baik, skor 4), Biru (baik, skor 3), Merah (buruk, skor 2), Hitam (sangat buruk, skor 1). Ukuran perusahaan diukur dengan kapitalisasi pasar. Logaritma natural dari kapitalisasi pasar digunakan untuk mengukur ukuran 
perusahaan dimana kapitalisasi pasar dipilih untuk mengurangi outlier dan tingginya tingkat kemiringan dari data mentah (Tabachnick dan Fidell, 2007). Tipe industri diukur dengan menggunakan variabel katagori. Pengakatagorian ini didasarkan pada Perpres No.61 tahun 2011 tentang RAN-GRK. Dimana nilai 1 untuk sektor pertanian, 2 untuk sektor energi dan transportasi, dan 3 untuk sektor industri dasar dan kimia. Retrun on asset diukur sebagai rasio laba sebelum bunga dan pajak pada akhir periode dengan total asset pada awal periode. Dan leverage diukur dengan membandingkan antara jumlah hutang.

\section{Penentuan Sampel}

Populasi yang digunakan dalam penelitian ini adalah seluruh perusahaan non keuangan yang terdaftar di BEI tahun 2014-2015. Sampel penelitian adalah perusahaan yang intensif menghasilkan emisi gas rumah kaca menurut RAN-GRK yaitu sektor pertanian, energi \& transportasi serta industri dasar dan kimia yang terdaftar di BEI tahun 2014-2015 yang berjumlah 298 perusahaan

Pengambilan sampel dengan teknik sampling. Teknik sampling yang diaplikasikan penelitian ini adalah nonrandom sampling, yaitu purposive sampling. Purposive sampling merupakan teknik pengambilan sampel berdasarkan pada tujuan, dimana sampel yang diambil telah ditentukan atau telah dipilih sesuai dengan tujuan penelitian yang akan dicapai

\section{Metode Analisis}

Pengujian hipotesis dalam penelitian ini menggunakan regresi logistic sebagai berikut:

VemD $=f\left(\alpha+\beta_{1} D_{\text {SML }}+\beta_{2}\right.$ PROPER +

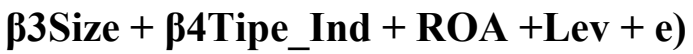

Keterangan :

$\alpha \quad$ : satuan konstan

VemD : variabel dikotom dari pengungkapan emisi gas rumah kaca dimana nilai 1 untuk perusahaan yang mengungkapkan informasi mengenai emisi gas rumah kaca dalam laporan mereka dan nilai 0 untuk perusahaan yang tidak mengungkapkan informasi mengenai emisi gas rumah kaca dalam laporan mereka.

DSML : variabel dummy dari sistem manajemen lingkungan dimana nilai 1 untuk perusahaan yang memiliki sistem manajemen lingkungan bersertifikat ISO 14001 atau memiliki sistem 
manajemen lingkungan tanpa

HASIL PENELITIAN

DAN

sertifikat, dan nilai 0 untuk

perusahaan yang tidak memiliki

sistem manajemen lingkungan.

PROPER: variabel kinerja

\section{PEMBAHASAN}

\section{Deskripsi Sampel Penelitian}

Perusahaan yang menjadi objek lingkungan yang diukur menggunakan indeks Peringkat PROPER. Dimana 5 untuk perusahaan yang mendapatkan peringkat emas, 4 untuk perusahaan yang mendapatkan peringkat hijau, 3 untuk perusahaan yang mendapatkan peringkat biru, 2 untuk perusahaan yang mendapatkan peringkat merah, 1 untuk perusahaan yang mendapatkan peringkat hitam, dan 0 untuk perusahaan yang tidak mendapatkan peringkat.

Size : logaritma natural dari kapitalisasi pasar

Tipe_Ind : variabel katagori, dimana 1 untuk sektor pertanian, 2 untuk sektor energi dan transportasi, dan 3 untuk sektor industri dasar dan kimia.

ROA : laba sebelum bunga dan pajak dibagi total asset Lev : total hutang dibagi total asset

dalam penelitian ini adalah perusahaan yang memiliki frekuensi penghasil emisi gas rumah kaca terbesar di Indonesia berdasarkan Perpres No. 61 tahun 2011 tentang RAN-GRK yaitu perusahaan bidang pertanian, energi dan transportasi, serta industri dasar dan kimia. Berikut merupakan rincian dari perusahaan yang digunakan sebagai objek penelitian (Tabel 1.) Perusahaan tersebut kemudian dikalsifikasikan berdasarkan kepemilikan sistem manajemen lingkungan, yang tersaji dalam Tabel 2.

Dari tabel tersebut dapat dilihat bahwa perusahaan yang memiliki SML akan lebih mengungkapkan emisi gas rumah kaca dengan persentase $74,4 \%$ sedangkan yang tidak memilki lebih tidak mengungkapkan emisi gas rumah kaca dengan persentase $72,8 \%$ dan hanya $27,2 \%$ saya yang tidak memiliki SML namun tetap mengungkapkan emisi gas rumah kaca.

Perusahaan dalam sampel penelitian juga dideskripsikan berdasarkan kinerja lingkungan, yang tersaji dalam Tabel 3.

Dari tabel tersebut dapat dilihat bahwa perusahaan yang mendapat peringkat 
5 akan lebih mengungkapkan emisi gas rumah kaca dengan persentase $100 \%$, yang mendapat peringkat 4 akan lebih mengungkapkan emisi gas rumah kaca dengan persentase $100 \%$, yang mendapat peringkat 3 akan lebih mengungkapkan emisi gas rumah kaca dengan persentase $63,3 \%$ dan yang tidak mengungkapkan memiliki persentase $36,7 \%$, yang mendapat peringkat 2 akan lebih mengungkapkan emisi gas rumah kaca dengan persentase $71,4 \%$ dan yang tidak mengungkapkan memiliki persentase $28,6 \%$, sedangkan yang tidak mendapat peringkat akan lebih banyak yang tidak mengungkapkan emisi gas rumah kaca dengan persentase $61,1 \%$ dan hanya 38,9\% yang tidak mendapat peringkat namun tetap mengungkapkan emisi gas rumah kaca.

\section{Tabel 1}

\section{Rincian Perolehan Sampel}

\begin{tabular}{clc}
\hline No. & \multicolumn{1}{c}{ Keterangan } & Jumlah \\
\hline 1. & $\begin{array}{l}\text { Perusahaan non keuangan yang terdaftar } \\
\text { di BEI tahun 2014-2015. }\end{array}$ & 854 \\
2. & $\begin{array}{l}\text { Perusahaan diluar bidang pertanian, } \\
\text { energi dan transportasi serta industri } \\
\text { dasar dan kimia yange terdaftar di BEI }\end{array}$ & $(544)$ \\
tahun 2014-2015 & \\
3. Perusahaan bidang pertanian, energi dna \\
transportasi serta industri dasar dan \\
kimia yang tidak menerbitkan laporan \\
tahunan selama 2014-2015
\end{tabular}

Sumber : Data sekunder yang diolah, 2017

Perusahaan tersebut kemudian

diklasifikasikan berdasarkan kepemilikan sistem manajemen lingkungan, yang tersaji dalam Table 2: 
Tabel 2

VemD*SML Crosstabulation

\begin{tabular}{lllrrr}
\hline & & \multicolumn{2}{c}{ SML } & \multicolumn{1}{c}{ Total } \\
\cline { 3 - 4 } & & \multicolumn{1}{c}{, $\mathbf{0 0}$} & $\mathbf{1 , 0 0}$ & \\
\hline \multirow{3}{*}{ VemD } & \multirow{2}{*}{$\mathbf{0 0}$} & Count & 123 & 33 & 156 \\
\cline { 2 - 5 } & \multirow{2}{*}{$\mathbf{1 , 0 0}$} & \% within SML & $72,8 \%$ & $25,6 \%$ & $52,3 \%$ \\
\hline \multirow{2}{*}{ Total } & Count & 46 & 96 & 142 \\
& & \% within SML & $27,2 \%$ & $74,4 \%$ & $47,7 \%$ \\
\hline & & Count & 169 & 129 & 298 \\
& & \% within SML & $100,0 \%$ & $100,0 \%$ & $100,0 \%$ \\
\hline
\end{tabular}

Sumber : Data sekunder yang diolah, 2017

Dari tabel tersebut dapat dilihat saya yang tidak memiliki SML namun tetap bahwa perusahaan yang memiliki SML mengungkapkan emisi gas rumah kaca. akan lebih mengungkapkan emisi gas rumah kaca dengan persentase 74,4\% Perusahaan dalam sampel penelitian sedangkan yang tidak memilki lebih tidak juga dideskripsikan berdasarkan kinerja mengungkapkan emisi gas rumah kaca lingkungan, yang tersaji dalam Tabel 3: dengan persentase $72,8 \%$ dan hanya $27,2 \%$

Tabel 3

VemD*PROPER Crosstabulation

\begin{tabular}{|c|c|c|c|c|c|c|c|c|}
\hline & & & \multicolumn{5}{|c|}{ PROPER } & \multirow{2}{*}{ Total } \\
\hline & & & ,00 & 2,00 & $\mathbf{3 , 0 0}$ & 4,00 & 5,00 & \\
\hline \multirow{4}{*}{ VemD } & \multirow[b]{2}{*}{,00 } & Count & 132 & 2 & 22 & 0 & 0 & 156 \\
\hline & & $\%$ within PROPER & $61,1 \%$ & $28,6 \%$ & $36,7 \%$ & $0,0 \%$ & $0,0 \%$ & $52,3 \%$ \\
\hline & \multirow{2}{*}{1,00} & Count & 84 & 5 & 38 & 10 & 5 & 142 \\
\hline & & $\%$ within PROPER & $38,9 \%$ & $71,4 \%$ & $63,3 \%$ & $100,0 \%$ & $100,0 \%$ & $47,7 \%$ \\
\hline \multirow{2}{*}{ Total } & & Count & 216 & 7 & 60 & 10 & 5 & 298 \\
\hline & & $\%$ within PROPER & $100,0 \%$ & $100,0 \%$ & $100,0 \%$ & $100,0 \%$ & $100,0 \%$ & $100,0 \%$ \\
\hline
\end{tabular}

Sumber : Data sekunder diolah pada tahun 2017

Dari tabel tersebut dapat dilihat 5 akan lebih mengungkapkan emisi gas bahwa perusahaan yang mendapat peringkat rumah kaca dengan persentase $100 \%$, yang 
mendapat peringkat 4 akan lebih mengungkapkan emisi gas rumah kaca dengan persentase $100 \%$, yang mendapat peringkat 3 akan lebih mengungkapkan emisi gas rumah kaca dengan persentase $63,3 \%$ dan yang tidak mengungkapkan memiliki persentase $36,7 \%$, yang mendapat peringkat 2 akan lebih mengungkapkan emisi gas rumah kaca dengan persentase $71,4 \%$ dan yang tidak mengungkapkan memiliki persentase $28,6 \%$, sedangkan yang tidak mendapat peringkat akan lebih banyak yang tidak mengungkapkan emisi gas rumah kaca dengan persentase $61,1 \%$ dan hanya $38,9 \%$ yang tidak mendapat peringkat namun tetap mengungkapkan emisi gas rumah kaca.

Perusahaan dalam sampel penelitian juga dideskripsikan berdasarkan tipe industri, yang tersaji dalam tabel 4:

Tabel 4

VemD*Tipe_Ind Crosstabulation

\begin{tabular}{|c|c|c|c|c|c|c|}
\hline & & & \multicolumn{3}{|c|}{ Tipe_Ind } & \multirow[t]{2}{*}{ Total } \\
\hline & & & 1,00 & 2,00 & 3,00 & \\
\hline \multirow{4}{*}{ VemD } & \multirow{2}{*}{, 00} & Count & 19 & 77 & 60 & 156 \\
\hline & & $\%$ within Tipe_Ind & $59,4 \%$ & $51,3 \%$ & $51,7 \%$ & $52,3 \%$ \\
\hline & \multirow{2}{*}{1,00} & Count & 13 & 73 & 56 & 142 \\
\hline & & $\%$ within Tipe_Ind & $40,6 \%$ & $48,7 \%$ & $48,3 \%$ & $47,7 \%$ \\
\hline \multirow[b]{2}{*}{ Total } & & Count & 32 & 150 & 116 & 298 \\
\hline & & $\%$ within Tipe_Ind & $\begin{array}{r}100,0 \\
\%\end{array}$ & $100,0 \%$ & $100,0 \%$ & $100,0 \%$ \\
\hline
\end{tabular}

Sumber : Data sekunder diolah pada tahun 2017

Dari tabel tersebut dapat dilihat bahwa perusahaan yang masuk kelompok 3 lebih banyak yang tidak mengungkapkan emisi gas rumah kaca dengan persentase $51,7 \%$ sedangkan yang mengungkapkan sebesar 48,3\%, yang masuk kelompok 2 lebih banyak yang tidak mengungkapkan emisi gas rumah kaca dengan persentase 51,3\% sedangkan yang mengungkapkan sebesar 48,7\%, yang masuk kelompok 1 lebih banyak yang tidak mengungkapkan emisi gas rumah kaca dengan persentase 59,4\% sedangkan yang mengungkapkan sebesar 40,6\%. Penggolongan tipe industri tidak memberikan perbedaan yang signifikan antara yang mengungkapkan dan yang tidak mengungkapakan emisi gas rumah kaca.

\section{Deskripsi Variabel}

Dari tabel 5 diketahui bahwa nilai rata-rata (mean) untuk yang 
mengungkapkan emisi gas rumah kaca lebih besar dibanding yang tidak mengungkapkan emisi gas rumah kaca. Perbedaan nilai mean yang ada pada variabel SIZE (28,6303 dengan 27,3874), ROA (2,8669 dengan -1,3079), dan leverage $(34,6322$ dengan 29,2946). Hal ini menunjukkan bahwa pengungkapan emisi gas rumah kaca lebih banyak dilakukan oleh perusahaan-perusahaan yang memiliki ukuran perusahaan yang besar, return on asset yang tinggi, dan leverage yang kecill dibanding dengan perusahaan-perusahaan yang tidak mengungkapkan emisi gas rumah kaca.

\section{Pembahasan Hasil Penelitian}

Berdasarkan penilaian kelayakan model regresi (goodness of test), nilai signifikansi Hosmer and Lemeshow Goodness-of-fit test statistics menunjukkan angka sebesar 0,883). Dengan demikian nilai tersebut lebih besar dari tingkat signifikan $\alpha=5 \%$. Hal ini menunjukkan bahwa model regresi logistic tersebut layak dipakai untuk menganalisis prediksi perusahaan melakukan pengungkapan emisi gas rumah kaca. Hasil pengujian hipotesis dapat dilihat pada Tabel 6

\section{Tabel 5}

\section{Statistik Deskriptif}

\begin{tabular}{|c|c|c|c|c|c|c|c|c|c|c|c|c|c|c|}
\hline & \multicolumn{4}{|c|}{ Seluruh Perusahaan } & \multicolumn{5}{|c|}{$\begin{array}{l}\text { Perusahaan yang Mengungkapkan } \\
\text { Emisi GRK }\end{array}$} & \multicolumn{5}{|c|}{$\begin{array}{c}\text { Perusahaan yang tidak } \\
\text { Mengungkapkan Emisi GRK }\end{array}$} \\
\hline & $\mathrm{N}$ & Min & Max & Mean & $\begin{array}{c}\text { Std. } \\
\text { Deviation }\end{array}$ & N Min & Max & Mean & $\begin{array}{c}\text { Std. } \\
\text { Deviation }\end{array}$ & $\mathrm{N}$ & Min & Max & Mean & $\begin{array}{c}\text { Std. } \\
\text { Deviation }\end{array}$ \\
\hline SIZE & 298 & 23,05 & 33,38 & 27,9797 & 1,91140 & 14224,48 & 33,38 & 28,6303 & 5,3441 & 156 & 23,05 & 31,76 & 27,3874 & 41,75713 \\
\hline ROA & 298 & $\begin{array}{c}- \\
172,82\end{array}$ & 36,58 & 0,6814 & 14,25118 & $142 \stackrel{-}{12,24}$ & 36,58 & 2,8669 & 6,81195 & $156_{1}$ & $\begin{array}{c}- \\
172,82\end{array}$ & 28,96 & $-1,3079$ & 18,40077 \\
\hline LEV & 298 & 0 & 240,53 & 32,0888 & 26,73716 & 1420 & 79,41 & 29,2946 & 18,15404 & 156 & 0 & 240,53 & 34,6322 & 232,50122 \\
\hline $\begin{array}{l}\text { Valid N } \\
\text { (listwise) }\end{array}$ & 298 & & & & & 142 & & & & 156 & & & & \\
\hline
\end{tabular}

Sumber : Data sekunder diolah pada tahun 2017 
Tabel 6

Hasil Uji Hipotesis

\begin{tabular}{lcc}
\hline & Variabel & $(\boldsymbol{p}$-value $)$ \\
\hline SML & $0,000^{*}$ \\
PROPER & $0,026^{*}$ \\
SIZE & $0,001^{*}$ \\
Tipe_Ind & $0,077^{*}$ \\
ROA & 0,319 \\
Leverage & $0,029^{*}$ \\
\hline
\end{tabular}

Keterangan: *) Signifikan

Hasil pengujian hipotesis pertama menunjukkan bahwa hipotesis pertama diterima. Penerimaan hipotesis pertama menunjukkan bahwa variabel sistem manajemen lingkungan berpengaruh positif signifikan terhadap pengungkapan emisi gas rumah kaca dengan nilai signifikansi sebesar 0,000. Alasan yang mendasari hasil penelitian adalah bahwa perusahaan dengan sistem manajemen lingkungan akan lebih fokus pada peningkatan pengelolaan lingkungan dan pengungkapan emisi gas rumah kaca(Psomas, 2011) Teori legitimasi menyatakan bahwa legitimasi bertujuan untuk memahami pengungkapan emisi gas rumah kaca perusahaan guna menyesuaikan diri dengan sosial (Rankin et al, 2011). Perusahaan yang kurang memenuhi legitimasinya, maka kepercayaan dan pengakuan masyarakat terhadap perusahaan akan terganggu. Perusahaan sebagai entitas yang memiliki banyak stakeholders dimana para stakeholder akan mengawasi dan menuntut perusahaan untuk memperhatikan segala kegiatan bisnisnya termasuk masalah lingkungan karena akan berdampak pada keberlangsungan perusahaan. Perusahaan harus memenuhi kebutuhan stakeholder termasuk memperhatikan masalah lingkungan agar tidak kehilangan dukungan dari stakeholder.

Hasil pengujian terhadap hipotesis kedua menunjukkan bahwa variabel kinerja lingkungan berpengaruh positif signifikan terhadap pengungkapan emisi gas rumah kaca dengan nilai signifikansi sebesar 0,026. Alasan yang mendasari hasil penelitian adalah teori legitimasi mengungkapkan bahwa ada kecenderungan perusahaan yang memiliki kinerja lingkungan baik akan melakukan pengungkapan lingkungan. Hal ini dilakukan agar kepercayaan masyarakat terhadap perusahaan tetap terjaga dan 
masyarakat tetap meberikan dukungan penuh kepada perusahaan. Teori stakeholder menyatakan pengungkapan lingkungan dapat dijadikan sarana perusahaan untuk memberitahu aktivitas lingkungan perusahaan kepada para stakeholder. Pengungkapan yang dilakukan perusahaan berkinerja lingkungan baik akan menjadi kabar baik bagi para stakeholder sehingga dapat menjadikan hubungan perusahaan dengan para stakeholder tetap harmonis (Verecchia, 1983; Suratno et al, 2006). Hal ini juga dilakukan untuk menunjukkan komitmen perusahaan terhadap lingkungan untuk memperoleh dukungan stakeholder dan legitimasi masyarakat (Lu dan Abeysekara, 2012).

Pengujian hipotesis ketiga menunjukkan bahwa variabel ukuran perusahaan berpengaruh

positif signifikan terhadap pengungkapan emisi gas rumah kaca dengan nilai signifikansi sebesar 0,001. Alasan yang mendasari adalah perusahaan besar lebih terbuka untuk umum dan pengawasan pemerintah sehingga mendorong pelaporan secara sukarela (Rankin et al, 2011). Perusahaan yang lebih besar lebih mungkin untuk memberikan pengungkapan secara sukarela karena mereka melakukan kegiatan yang memepengaruhi lingkungan, sehingga menimbulkan pengawasan yang lebih besar dari publik dan pemerintah (Stanny dan Ely, 2008; Prado-Lorenzo et al, 2009). Selain itu perusahaan-perusahaan besar umumnya memiliki lebih pemegang saham yang mungkin tertarik pada perubahan sosial dan kegiatan lingkungan (Cowen et al, 1987).

Pengujian hipotesis keempat menunjukkan bahwa variabel tipe industri berpengaruh positif signifikan terhadap pengungkapan emisi gas rumah kaca dengan nilai signifikansi sebesar 0,077. Alasan yang mendasari adalah pengendalian emisi gas rumah kaca secara langsung akan mempengaruhi industri energi atau industri-industri yang mengandalkan bahan bakar untuk mengendalikan peralatan atau kendaraan, pembangkit listrik, dan bahan bakar untuk transportasi (Choi et al, 2013). Tipe industri berhubungan dengan legitimasi dan teori stakeholder. Dimana perusahaan yang high profile harus lebih mengungkapkan emisi gas rumah kacanya untuk meningkatkan nilai perusahaan serta untuk mendapatkan dukungan dari masyarakat dan stakeholder selain itu juga bisa dijadikan keunggulan bersaing dari perusahaan yang low profile. Dengan demikian, tipe industri akan mempengaruhi kesukarelaan dalam pengungkapan emisi gas rumah kaca. 
Pengujian hipotesis kelima informasi keberhasilan keuangan menunjukkan variabel return on asset tidak perusahaan.

berpengaruh positif signifikan terhadap pengungkapan emisi gas rumah kaca dengan nilai signifikansi sebesar 0,319. Hasil analisis tersebut tidak konsisten dengan hasil penelitian Clarkson et al, 2008 menyimpulkan bahwa perusahaan yang memiliki keuntungan lebih mungkin untuk memberikan pengungkapan lingkungannya.

Dan juga tidak sejalan dengan penelitian Lorenzo et al (2009), perusahaan dengan profitabilitas tinggi lebih mampu dalam melakukan pengungkapan dibandingkan dengan perusahaan dengan profitabilitas rendah. Akan tetapi hasil analisis tersebut konsisten dengan penelitian dari Rankin et al (2011), Lorenzo et al (2009), Pardini (2013), dan Freedman dan Jaggi (2005) yang tidak menemukan pengaruh yang signifikan antara return on asset dengan pengungkapan emisi gas rumah kaca. Neu et al (1998) menemukan perusahaan yang dengan profitabilitas tidak menguntungkan justru mengambil keuntungan dari pengungkapan lingkungan untuk tujuan legitimasi. Sebaliknya, perusahaan dengan profitabilitas yang menguntungkan tidak perlu untuk memperluas pengungkapan lingkungan mereka karena mereka takut bahwa pengungkapan dapat mengganggu
Pengujian hipotesis keenam menunjukkan bahwa variabel leverage berpengaruh negatif

signifikan terhadap pengungkapan emisi gas rumah kaca dengan nilai signifikansi sebesar 0,029. Alasan yang medasari adalah perusahaan dengan leverage yang tinggi akan lebih berhati-hati dalam mengurangi dan mengungkapkannya terutama menyangkut mengenai pengeluaranpengeluaran yang berkaitan dengan tindakan pencegahan karbon (Luo et al, 2013). Perusahaan dengan leverage yang tinggi cenderung lebih berkonsentrasi dalam melunasi kewajiban dibandingkan dengan melakukan pengungkapan sukarela. Hal ini disebabkan karena ketebatasan alokasi dana yang dimiliki, perusahaan harus memilih apakah menggunakan dana tersebut untuk melunasi segala kewajiban mereka ataukah untuk melakukan pengungkapan sukarela.

\section{KESIMPULAN}

Hasil penelitian ini juga menunjukkan beberapa faktor yang mempengaruhi pengungkapan emisi gas rumah kaca. Dari enam faktor yang diteliti (sistem manajemen lingkungan, kinerja 
lingkungan, ukuran perusahaan, tipe industri, return on asset, dan leverage), terbukti sistem manajemen lingkungan, kinerja lingkungan, ukuran perusahaan, tipe industri, dan leverage berpengaruh positif terhadap pengungkapan emisi gas rumah kaca. Hal ini berarti keberadaan sistem manajemen lingkungan, peringkat PROPER yang tinggi, perusahaan yang besar, industri yang insentif, dan leverage yang kecil mendorong perusahaan untuk mengungkapkan emisi gas rumah kaca. Sedangkan faktor return on asset terbukti tidak berpengaruh terhadap pengungkapan emisi gas rumah kaca. Hal ini berarti manajer perusahaan tidak terlalu mempertimbangkan return on asset dalam mengambil keputusan untuk mengungkapkan emisi gas rumah kaca atau tidak.

Penelitian ini memiliki beberapa keterbatasan. Pertama, terdapat perbedaan penilaian dalam menganalisis dan mengidentifikasi variabel pengungkapa emisi gas rumah kaca dan sistem manajemen lingkungan pada laporan tahunan perusahaan karena terdapat unsur subjektivitas pada masing-masing peneliti. Kedua, dalam penelitian ini mengukur pengungkapan emisi gas rumah kaca dan sistem manajemen lingkungan hanya didasarkan pada data di laporan tahunan, mungkin akan ada kemungkinan bahwa perusahaan telah membuat pengungkapan publik dan sistem manajemen lingkungan dalam bentuk lain yang peneliti tidak sadar.

Atas dasar keterbatasan tersebut, untuk penelitian selanjutnya disarankan untuk menambah periode penelitian serta menambah sektor perusahaan yang diteliti. Kedua, penelitian selanjutnya disarankan untuk menambah variabel independen yang sesuai dengan topik penelitian dan mampu menjelaskan variabel dependen secara lebih baik. Dan ketiga, penelitian selanjutnya disarankan untuk menambah sumber data selain dari laporan tahunan perusahaan.

\section{REFERENSI}

Berthelot, Robert, 2011. Climate change disclosure: An examination of Canadian oil and gas firms. Issues in Social and Enviromental Accounting, Volume 5 No. 1, Pp 106-123.

Borghei, Zahra., Philomena Leung, \& James Guthrie, (2016),"The nature of Voluntary greenhouse gas disclosure - an explanation of the changing rationale: Australian evidence", Meditari Accountancy Research, Vol. 24 Iss 1 pp. -

Carbon Disclosure Project (CDP) (2009), "Carbon Disclosure Project report 2009: Australia And Newe Zealand", available at:www.cdproject.net/download.asp? 
file1/4CDP7_Australia_New_Zealand _Report.pdf

Choi, Bo Bae., Lee, Doowon dan Psaros, Jim, (2013), "An Analysis of Australian Company Carbon Emission Disclosure", Pacific Accounting Review, Vol.25 Iss 1 pp.58-79

Clarkson, P.M., Li, Y., Richardson, G.D. and Vasvari, F.P. (2008), Revisiting the relation between environmental performance and environmental disclosure: an empirical analysis", Accounting, Organizations and Society, Vol. 33, pp. 303-27.

Cowen, S.S., Ferreri, L.B. and Parker, L.D. (1987), "The impact of corporate characteristics on social responsibility disclosure: a typology and frequencybased analysis", Accounting, Organizations and Society, Vol. 12 No. 2, pp. 111-22.

Dawkins, Cedric dan Fraas, John, (2011), "Comming clean: the impact Environmental performance and visibility on corporate climate change disclosure", Journal Business Ethicss, 100(2): 303-322

Freedman, Martin, \& Jaggi, Bikki, (2005)," Global warming, commitment to the Kyoto protocol, and accounting disclosures by the largest global public firms from polluting industries", The International Journal of Accounting, Vol 40 , pp.216

Ghomi \& Leung, 2013. An Empirical Analysis of The Determinants of Greenhouse Gas Voluntary Disclosure in Australia. Accounting and Finance Research, Vol. 2 No. 1, 110-127.
Gonzalez, Jose Maria., Gonzalez, \& Constancio Zamora Ramírez,(2016),"Voluntary carbon disclosure by Spanish companies: an empirical analysis", International Journal of Climate Change Strategies and Management, Vol. 8 Iss 1 pp. 57 $-79$

Griffiths, A., Haigh, N. and Rassias, J. (2007), “A framework for understanding institutional governance system and climate change: the case of Australia", European Management Journal, Vol. 25 No. 6, pp. 415

International Panel on Climate Change (IPCC, (2007), Climate Change, 2007 : Assesment Report 4, IPCC, Geneva.

Lang, M. and Lundholm, R. (1993), "Crosssectional determinants of analyst ratings of Corporate disclosures", Journal of Accounting and Research, Vol. 31 No. 2, pp. 246-7

Liesen, Andrea., Andreas., G. Hoepner, \& Dennis M. Patten Frank Figge , (2015),"Does stakeholder pressure influence corporate GHG emissions reporting? Empirical evidence from Europe", Accounting, Auditing \& Accountability Journal, Vol. 28 Iss 7 pp. $1047-1074$

Luo, Le., Qingliang Tang, \& Yi-Chen Lan, (2013), "Comparison of propensity for carbon disclosure between developing and developed countries", Accounting Research Journal, Vol. 26 Iss 1 pp. $6-34$

Martin, Francisco Díez., Camilo PradoRoman Alicia Blanco-González , (2013),"Beyond legitimacy: legitimacy types and organizational 
success", Management Decision, Vol. 51 Iss 10 pp. $1954-1969$

Neu, D., H. Warsame. and K.Pedwell. 1998. "Managing public impressions: environmental disclosures in annual reports." Accounting, Organizations and Society, Vol. 23, pp. 265-282

Owen, David, (2008),"Chronicles of wasted time?", Accounting, Auditing \& Accountability Journal, Vol. 21 Iss 2 pp. $240-267$

Pradini, Harlinda Siska. 2013. The Analysis of Information Content towards Greenhouse Gas Emissions Disclosure in Indonesia Companies. Thesis pada Universitas Diponegoro Semarang.

Prado-Lorenzo, J., Rodriguez-Dominguez, L., Gallego-A' lvarez, I. and GarciaSa'nchez, I. (2009), "Factors influencing the disclosure of greenhouse gas emissions in companies world-wide", Management Decision, Vol. 47 No. 7 , pp. 1133-57.

PricewaterhouseCoopers (PWC) (2008), "Carbon countdown: a survey of executive opinion onclimate change in the countdown to a carbon economy", January, available at: www.pwc.com/Extweb/onlineforms. nsf/docid/0EDACFFBA83712AB852 573DB000F55FF/\$file/CarbonCount down.pdf

\begin{tabular}{llr} 
Psomas, Evangelos & \multicolumn{2}{c}{ Christos V., } \\
Fotopoulos & Dimitrios & P., \\
Kafetzopoulos, & \multicolumn{2}{c}{$(2011)$, "Motives, } \\
difficulties and benefits in & ind \\
implementing the ISO & 14001 \\
Environmental & & Management \\
System", & Management of
\end{tabular}

Environmental Quality: An International Journal, Vol. 22 Iss 4 pp. $502-521$

Purnomosidhi, Bambang. 2006. Praktik Pengungkapan Modal Intelektual Pada Perusahaan Publik di BEJ. Malang: Universitas Brawijaya Malang

Rankin, M., Windsor, C. and Wahyuni, D. (2011), "An investigation of volauntary Corporate greenhouse gas emissions reporting in a market governance system: Australian evidence.", Accounting, Auditing \& Accountability Journal, Vol. 24 No. 8, pp. 1037- 1070.

Republik Indonesia. 1994. Undang-Undang No. 17 Tahun 2004tentang Pengesahan Kyoto Protocol To The United Nations Framework Convention On Climate Change (Protokol Kyoto Atas Konvensi Kerangka Kerja Perserikatan Bangsa-Bangsa Tentang Perubahan Iklim). Lembaran Negara RI Tahun 2004, No. 72. Sekretariat Negara. Jakarta.

Republik Indonesia. 2011. Peraturan Presiden No. 61 Tahun 2011tentang Rencana Aksi Nasional Penurunan Emisi Gas Rumah Kaca. Sekretariat Kabinet RI. Jakarta.

Republik Indonesia. 2011. Peraturan Presiden No. 71 Tahun 2011tentang Penyelenggaraan Inventarisasi Gas Rumah Kaca Nasional. Sekretariat Kabinet RI. Jakarta.

Stanny, E. and Ely, K. (2008), “Corporate environmental disclosures about the effects of climate change", Corporate Social Responsibility and Environmental Management, Vol. 15, pp. 338-48. 
Suratno, Darsono, dan Siti Mutmainah. 2006. Pengaruh Enviromental Performance Terhadap Enviromental Disclosure dan Economic Performance : Studi Empiris Pada Perusahaan Manufaktur Yang Terdaftar Di Bursa Efek Jakarta Periode 2001-2004. SNA IX Padang. 23- 26 Agustus.

Tabachnick, F.G. and Fidell, L.S. (2007), Using Multivariate Statistics, 5th ed., Pearson Education, Boston, MA.

United Nations (1997), "Kyoto Protocol to the United Nations Framework Convention on Climate Change", available at: http://unfccc.int/resource/docs/convk p/kpeng.pdf

Verrecchia, Robert E., 1983. Discretionary Disclosure. Journal of Accounting and Economics Vol. 5, 179-194.

Wang et, al, 2011. Quantifying The Impact of Financial Development on Economic Development. Review of Economic Dynamics 